\title{
Presupuestos locales
}

\author{
Domingo Jesús Jiménez-VALLAdOLID De L’Hotellerie-Fallois \\ Profesor Contratado Doctor de Derecho Financiero y Tributario \\ Universidad Autónoma de Madrid \\ César MARTínez SÁNCHEZ \\ Profesor Contratado Doctor de Derecho Financiero y Tributario \\ Universidad Autónoma de Madrid \\ Neus TEIXIDOR MARTíNEZ \\ Abogada e Investigadora en formación \\ Universidad Autónoma de Madrid
}

\begin{abstract}
Palabras clave: haciendas locales; presupuestos locales; estabilidad presupuestaria.
\end{abstract}

Keywords: local finance; local budgets; budgetary stability.

SUMARIO: I. INTRODUCCIÓN.-II. PRESUPUESTOS LOCALES Y ESTABILIDAD PRESUPUESTARIA: 1. Novedades normativas. 2. Novedades jurisprudenciales. 3. Novedades doctrinales.-III. EL CONTROL EXTERNO DE LA ACTIVIDAD ECONOMICO-FINANCIERA LOCAL: 1 . La fiscalización externa de la actividad económico-administrativa de las entidades locales: 1.1 Marco normativo en materia de fiscalización. 1.2 Tribunal de Cuentas. 1.3. Cámara de Cuentas de la Comunidad de Madrid. 2. Responsabilidad contable: 2.1. Tribunal Supremo. 2.2. Tribunal de Cuentas. 3. Novedades doctrinales.

\section{INTRODUCCIÓN}

La actividad financiera del Estado está compuesta esencialmente por dos elementos: los ingresos y los gastos públicos. Correlativamente, el derecho tributario se ocupa del estudio del régimen jurídico relativo a la obtención de los ingresos necesarios para la satisfacción de las necesidades públicas. Por su parte, el derecho presupuestario se encarga del conjunto de reglas y principios que disciplinan el gasto público. Desde hace años, es pacífica entre la doctrina científica, al menos entre la mayoritaria, la idea de que la 
conexión entre el ingreso y el gasto público es la esencia de la actividad financiera y, por tanto, su análisis científico debe realizarse de forma unitaria, con una metodología común y a la luz de unos principios comunes. Esto explica que, durante varias ediciones de este anuario y hasta hace solo cinco años, el análisis de las Haciendas locales se realizase en un único informe.

Sin embargo, en los últimos años se ha incrementado notablemente la preocupación por el control del gasto público y la adecuada rendición de cuentas de los gestores públicos. Esto se ha traducido en una revitalización del derecho presupuestario, de suerte que se han incrementado tanto las obligaciones de control previo (instrumentadas principalmente a través de los interventores en las fases previas a la aprobación definitiva del gasto), así como el alcance y la intensidad de los controles a posteriori, llevados a cabo - en la mayoría de las ocasiones - por el Tribunal de Cuentas. Asimismo, la transparencia y claridad de las cuentas públicas locales son también requisitos para la obtención de los fondos provenientes de la Administración central, a fin de hacer frente a las imperiosas necesidades de liquidez que afrontan los municipios en la actualidad.

Sentado lo anterior, y a la vista del éxito que tuvo la iniciativa en los años anteriores, parece que está más que justificado dividir el análisis de las Haciendas locales en dos informes separados: uno que analice la vertiente del ingreso, y otro, el presente, que se refiera al régimen jurídico del gasto, con especial consideración de la fiscalización externa de las entidades locales y de la responsabilidad contable que pueda derivarse.

Con carácter previo al análisis pormenorizado de las novedades relativas a esta materia, debe destacarse el gran impacto que la pandemia de covid-19 ha tenido sobre las reglas fiscales en general y, especialmente, sobre aquellas que disciplinan la actividad de las entidades locales.

En efecto, el notable efecto económico de la pandemia no solo ha llevado a una suspensión de los objetivos presupuestarios a medio plazo mediante la activación de la denominada cláusula de salvaguardia, sino que también ha provocado otras tres respuestas de gran calado por parte de las instituciones de la UE: la flexibilización temporal de la prohibición de ayudas de Estado; la adopción del plan denominado NextGenerationEU, que es un instrumento temporal de recuperación, dotado de 750.000 millones de euros, destinado a reparar los daños económicos y sociales inmediatos causados por la pandemia de coronavirus, cuyo elemento central lo constituye el Mecanismo Europeo de Recuperación y Resiliencia, que supondrá un total de 672.500 millones de euros en préstamos y subvenciones disponibles para apoyar las reformas e inversiones emprendidas por los países de la UE; y, por último, un muy extenso programas de compra de activos por parte del Banco Central Europeo, con el objetivo de apoyar la estabilización de los mercados financieros y proporcionar una amplia liquidez.

Tras la activación de la cláusula de salvaguardia en el ámbito europeo, el 20 de octubre de 2020 el Congreso de los Diputados apreció, en una resolución hasta entonces inédita, que España sufría una emergencia extraordinaria por la pandemia de covid-19 
que justificaba la suspensión temporal de las reglas fiscales en 2020 y 2021, en aplicación de lo dispuesto en el art. 135.4 de la Carta Magna.

A pesar de la incertidumbre que pudiera existir en torno a las concretas consecuencias de la declaración del Congreso, lo cierto es que en general se ha asumido la interpretación dada por el Ministerio de Hacienda, que consiste en que no solo han quedado en suspenso los objetivos de déficit y deuda para 2020 y 2021, sino que también se extiende a la regla de gasto, al destino obligatorio del superávit y a las medidas correctivas y coercitivas, salvo las medidas automáticas de corrección previstas en el art. 20 de la LOEPSF ${ }^{1}$.

\section{PRESUPUESTOS LOCALES Y ESTABILIDAD PRESUPUESTARIA}

\section{Novedades normativas}

Como hemos anticipado, la crisis sanitaria generada por la pandemia creada por la covid-19 ha tenido importantes repercusiones en el ámbito de los presupuestos de las entidades locales. El pasado 11 de febrero de 2020, antes de que la pandemia se hubiera extendido por España, el Consejo de Ministros hizo públicos sus Acuerdos por el que se adecúan los objetivos de estabilidad presupuestaria y de deuda pública para el conjunto de Administraciones públicas y de cada uno de sus subsectores para el año 2020 para su remisión a las Cortes Generales, y se fija el límite de gasto no financiero del presupuesto del Estado para 2020; y por el que se fijan los objetivos de estabilidad presupuestaria y de deuda pública para el conjunto de Administraciones públicas y de cada uno de sus subsectores para el periodo 2021-2023 para su remisión a las Cortes Generales, y el límite de gasto no financiero del presupuesto del Estado para 2021.

No obstante lo anterior, la declaración del estado de alarma a través del Real Decreto 463/2020, de 14 de marzo, por el que se declara el estado de alarma para la gestión de la situación de crisis sanitaria ocasionada por la covid-19, cambió la situación. De modo casi inmediato, se aprobó el Real Decreto-ley 8/2020, de 17 de marzo, de medidas urgentes extraordinarias para hacer frente al impacto económico y social de la covid-19, cuyo art. 3 permitía a las entidades locales destinar el superávit presupuestario correspondiente a 2019 a la financiación de gastos de inversión incluidos en la política de gastos correspondiente a servicios sociales y promoción social, incluyendo dentro de esta política, de modo excepcional, el gasto correspondiente a la financiación de prestaciones que tuvieran por objeto exclusivo el hacer frente a las situaciones extraordinarias derivadas de la covid-19. Este real decreto-ley fue objeto de convalidación por acuerdo del Congreso recogido en la Resolución de 25 de marzo de 2020, del Congreso de los Diputados,

1 Esta es la opinión expresada en el documento «Preguntas frecuentes sobre las consecuencias de la suspensión de las reglas fiscales en 2020 y 2021 en relación con las Comunidades Autónomas y las entidades locales», disponible en https://www.hacienda.gob.es/CDI/Estabilidad\%20Presupuestaria/FAQ_SUSPENSI\%C3\%93N_ DE_REGLAS_FISCALES.pdf. 
por la que se ordena la publicación del Acuerdo de convalidación del Real Decreto-ley 8/2020, de 17 de marzo, de medidas urgentes extraordinarias para hacer frente al impacto económico y social de la covid-19.

Este precepto fue objeto de desarrollo a continuación por el Real Decreto-ley 11/2020, de 31 de marzo, por el que se adoptan medidas urgentes complementarias en el ámbito social y económico para hacer frente a la covid-19, cuyo art. 20 establece el sistema de aplicación de lo previsto en el art. 3 del Real Decreto-ley 8/2020. Además, este real decretoley procedió a aprobar un aplazamiento extraordinario del calendario de reembolso en préstamos concedidos por Comunidades Autónomas y entidades locales a empresarios y autónomos afectados por la crisis sanitaria provocada por la covid-19 (art. 50) y un refuerzo de las obligaciones de suministro de información económico-financiera que afectan, entre otras, a las corporaciones locales (art. 51). Este real decreto-ley fue objeto de convalidación por acuerdo del Congreso recogido en la Resolución de 9 de abril de 2020, del Congreso de los Diputados, por la que se ordena la publicación del Acuerdo de convalidación del Real Decreto-ley 11/2020, de 31 de marzo, por el que se adoptan medidas urgentes complementarias en el ámbito social y económico para hacer frente a la covid-19.

En junio, el Gobierno aprobó otro real decreto-ley con implicaciones en los presupuestos de las entidades locales, aunque de un menor calado. Se trata del Real Decreto-ley 23/2020, de 23 de junio, por el que se aprueban medidas en materia de energía y en otros ámbitos para la reactivación económica. El art. 6 de este real decreto-ley establecía que las entidades locales podrían destinar en 2020, como máximo, el 7 por 100 del saldo positivo correspondiente al año 2019 para financiar gastos de inversión en vehículos eléctricos puros o con etiqueta ambiental CERO. Este real decreto-ley fue objeto de convalidación por acuerdo del Congreso recogido en la Resolución de 15 de julio 2020, del Congreso de los Diputados, por la que se ordena la publicación del Acuerdo de convalidación del Real Decreto-ley 23/2020, de 23 de junio, por el que se aprueban medidas en materia de energía y en otros ámbitos para la reactivación económica.

A continuación, el Gobierno publicó el Real Decreto-ley 27/2020 de 4 de agosto, de medidas financieras, de carácter extraordinario y urgente, aplicables a las entidades locales. Como es sabido, este real decreto-ley establecía, entre otros, un sistema para la cesión de los remanentes de las entidades locales a favor de la Administración central. Este real decreto-ley, sin embargo, fue derogado por Acuerdo del Congreso que se recoge en la Resolución de 10 de septiembre de 2020, del Congreso de los Diputados, por la que se ordena la publicación del Acuerdo de derogación del Real Decreto-ley 27/2020, de 4 de agosto, de medidas financieras, de carácter extraordinario y urgente, aplicables a las entidades locales. Debe tenerse en cuenta que el real decreto-ley contenía otras medidas distintas de la cesión de remanentes como eran las relativas a la prórroga del destino del superávit de 2018 y 2019 a inversiones financieramente sostenibles (arts. 1 y 2) o autorizaciones de créditos extraordinarios para la recuperación económica y social de las entidades locales (art. 4) y para el apoyo a los servicios de transporte público de titularidad de entidades 
locales (art. 5), entre otras. Debe tenerse en cuenta que, durante la vigencia de este real decreto-ley se publicó la Resolución de 10 de agosto de 2020, de la Dirección General del Tesoro y Politica Financiera, por la que se establecen las condiciones financieras aplicables a las operaciones de préstamo entre la Administración General del Estado y las entidades locales, según los términos previstos en el Real Decreto-ley 27/2020, de 4 de agosto, de medidas financieras, de carácter extraordinario y urgente, aplicables a las entidades locales.

Como consecuencia de la derogación del Real Decreto-ley 27/2020, el Consejo de Ministros, en su sesión de 6 de octubre de 2020, decidió aprobar una elevación del techo de gasto para 2021 y la suspensión de las reglas fiscales para los años 2020 y 2021 con el objeto de que la senda de estabilidad vigente quedara anulada y sin que el nuevo techo de gasto fuera acompañado de unos nuevos objetivos de estabilidad. Esta suspensión se justificaba en la activación de la cláusula general de salvaguardia del Pacto de Estabilidad y Crecimiento que anunció la Comisión Europea en marzo de 2020 y que se ha extendido a 2021 [Comunicación de la Comisión al Consejo relativa a la activación de la cláusula general de salvaguardia del Pacto de Estabilidad y Crecimiento, COM (2020)123 final; Declaración de los ministros de Hacienda de la UE sobre el Pacto de Estabilidad y Crecimiento habida cuenta de la crisis de la covid-19 de 23 de marzo de 2020, y Comunicación de la Comisión al Parlamento Europeo, al Consejo Europeo, al Consejo, al Banco Central Europeo, al Comité Económico y Social Europeo, al Comité de las Regiones y al Banco Europeo de Inversiones Estrategia anual de crecimiento sostenible 2021, COM/2020/575 final.

Para proceder a esta suspensión, el Gobierno solicitó al Congreso de los Diputados la declaración de situación de emergencia extraordinaria a los efectos del art. 135.4 de la Constitución y, de conformidad con el procedimiento previsto en el art. 11.3 de la Ley Orgánica 2/2012, de 27 de abril, de Estabilidad Presupuestaria y Sostenibilidad Financiera. Asimismo (LOEPSF), se suspendieron expresamente los Acuerdos del Consejo de Ministros de 11 de febrero de 2020 a los que nos hemos referido anteriormente, de modo que: «los objetivos de estabilidad y de deuda pública, y la regla de gasto, aprobados por el Gobierno el 11 de febrero de 2020, son inaplicables al aprobar este su suspensión ${ }^{2}$.

El Congreso de los Diputados, en su sesión de 20 de octubre de 2020, aprobó por mayoría absoluta que la situación derivada de la crisis pandémica debía ser considerada como de emergencia extraordinaria a los efectos de suspender las reglas fiscales. De acuerdo con la guía publicada por el Ministerio de Hacienda a la que nos hemos referido en la primera nota al pie de este trabajo: «Al suspenderse las reglas fiscales no resultan de aplicación las medidas correctivas y coercitivas que establece la LOEPSF ni en $2020 \mathrm{ni}$ en 2021, ni en referencia a 2020 y a 2021, salvo las medidas automáticas de corrección previstas en el art. 20 de la LOEPSF. En consecuencia, en 2020 no se aplicarán aquellas medidas en relación con incumplimientos en 2019 de reglas fiscales constatados con las liquidaciones de presupuestos, o con los estados contables del cierre del ejercicio. En 
2021 y 2022 tampoco se aplicarán en relación con los resultados de las liquidaciones de 2020 y 2021, respectivamente. Por ello, en esos años, no se exigirá la presentación de planes económico-financieros ni su aprobación, ni se aplicarán medidas como la adopción de acuerdos de no disponibilidad de créditos con origen en aspectos relativos a la presentación o aprobación de dichos planes o al cumplimiento de las reglas».

En relación con los ingresos de las entidades locales, el Real Decreto-ley 22/2020, de 16 de junio, por el que se regula la creación del Fondo covid-19 y se establecen las reglas relativas a su distribución y libramiento, establece el sistema de participación de las entidades locales en este fondo. De modo similar, el Real Decreto-ley 36/2020, de 30 de diciembre, por el que se aprueban medidas urgentes para la modernización de la Administración pública y para la ejecución del Plan de Recuperación. Transformación y Resiliencia identifica a las entidades locales como posibles beneficiarias del plan, estableciendo que «los ingresos por transferencias recibidas de la Administración General del Estado, procedentes del Mecanismo para la Recuperación y Resiliencia y del REACT-EU, están legalmente afectados a financiar los proyectos o líneas de acción que se integren dentro del Plan de Recuperación, Transformación y Resiliencia, con el grado de detalle especificado en el mismo».

También tiene implicaciones en los ingresos de las entidades locales el Real Decretoley 20/2020, de 29 de mayo, por el que se establece el ingreso minimo vital, cuya Disposición final sexta establece un sistema para asegurar la financiación de los gastos derivados de las funciones que puedan realizar las entidades locales en aplicación de la colaboración interadministrativa con el Instituto Nacional de la Seguridad Social que prevé el real decreto-ley. En otro orden de cosas, el Real Decreto-ley 34/2020, de 17 de noviembre, de medidas urgentes de apoyo a la solvencia empresarial y al sector energético, y en materia tributaria, ha venido a extender, a través de su art. 10, la vigencia de determinados preceptos de la Ley 6/2018, de 3 de julio, de Presupuestos Generales del Estado para el año 2018 a efectos del cálculo de la participación de los municipios en los tributos del Estado. Previamente al comienzo de la crisis sanitaria, se aprobó el Real Decreto-ley 2/2020, de 21 de enero, por el que se aprueban medidas urgentes en materia de retribuciones en el ámbito del sector público, que contiene algunas medidas que establecen límites presupuestarios para las retribuciones en el ámbito local.

Por último, la Ley 11/2020, de 30 de diciembre, de Presupuestos Generales del Estado para el año 2021, además de incluir las previsiones relativas a las participaciones de las entidades locales en los tributos del Estado, compensaciones, etc., ha modificado el art. 212 del texto refundido de la Ley reguladora de las Haciendas Locales, aprobado por Real Decreto legislativo 2/2004, de 5 de marzo (TRLRLHL) relativo a la rendición, publicidad y aprobación de la cuenta general. La Disposición adicional centésima octava, por su parte, prevé la posibilidad de concertar nuevas operaciones de endeudamiento para cancelar parcial o totalmente su deuda pendiente con el Fondo en liquidación para la Financiación de los Pagos a Proveedores, mientras que la Disposición adicional centésima séptima prevé la modificación del ámbito objetivo del Fondo de Ordenación, 
compartimento del Fondo de Financiación a Entidades Locales, incluyendo las cuantías que estén pendientes de amortizar y que correspondan a operaciones que se formalizaron en el marco de la línea de crédito para la cancelación de deudas de las entidades locales con empresas y autónomos. Además, la Disposición adicional centésima novena autoriza excepcionalmente y bajo determinadas circunstancias en 2021 la formalización de operaciones de conversión de deuda a corto plazo que estén vigentes en operaciones de crédito a largo plazo.

Además de lo anterior, ha de hacerse referencia a la Resolución de 11 de agosto de 2020, de la Secretaría General de Financiación Autonómica y Local, por la que se desarrolla la información a suministrar por las corporaciones locales relativa al esfuerzo fiscal de 2018 y su comprobación en las Delegaciones de Economía y Hacienda.

\section{Novedades jurisprudenciales}

La actividad de nuestros tribunales durante el año 2020 en relación con los presupuestos locales y el principio de estabilidad presupuestaria ha sido menos intensa que en años anteriores. Sin perjuicio de ello, merece la pena destacar los siguientes pronunciamientos recaídos en esta materia durante 2020.

En primer lugar, cumple reseñar la Sentencia del Tribunal Superior de Justicia (TSJ) de Cataluña de 14 de enero de 2020 (ECLI:ES:TSJCAT:2020:5382), en que se anula el acuerdo del Pleno de un ayuntamiento por el que se aprueba definitivamente el presupuesto general de un municipio por no haber incluido ninguna partida para el abono del justiprecio derivado de una expropiación forzosa. El TSJ de Cataluña, de acuerdo con la doctrina del Tribunal Supremo, entiende que el procedimiento expropiatorio se inicia con la solicitud del propietario, siendo obligado el pago del justiprecio tras su determinación en un plazo máximo de seis meses, por lo que la no inclusión en el presupuesto general municipal de la cantidad destinada a hacer frente al pago del justiprecio determina la nulidad del presupuesto.

Por otro lado, en la sentencia del TSJ de Castilla-La Mancha de 12 de mayo de 2020 (ECLI:ES:TSJCLM:2020:881) se impugna el acuerdo de la asamblea de un consorcio por el que se aprobó definitivamente el presupuesto general. Los recurrentes planteaban la nulidad del acuerdo en la medida en que los presupuestos no incluían a los órganos autónomos dependientes (en este caso, una sociedad mercantil de titularidad única del consorcio cuya disolución se había acordado, pero no materializado), no se incluyó el informe del consejo de administración del consorcio en la convocatoria del Pleno de la asamblea para la aprobación de los presupuestos; las omisiones en el anexo de inversiones, al reiterar únicamente lo estados de cuentas incluidos en el presupuesto; entre otros motivos. El TSJ acoge todos los motivos de impugnación anulando los presupuestos del consorcio.

Además, de las anteriores, merece la pena destacar la sentencia del TSJ de Cataluña de 28 de septiembre de 2020 (ECLI:ES:TSJCAT:2020:8060) en que se anula el acuerdo 
de aprobación de determinados gastos y de reconocimiento de crédito por determinadas facturas. Estos gastos habían sido informados desfavorablemente por la Intervención municipal ya que los servicios prestados por las entidades que daban lugar a los referidos gastos no se encontraban sustentados en contratos vigentes y no habían sido sometidos al trámite de fiscalización previa por la intervención. El TSJ considera que la no existencia de contratos que den cobertura legal a los pagos que se tratan de realizar determina la nulidad de los acuerdos de aprobación de los gastos referidos y del reconocimiento de créditos para el pago de las facturas.

Por último, debe señalarse que la sentencia del TSJ de Cataluña de 12 de febrero de 2020 (ECLI:ES:TSJCAT:2020:3838) considera la existencia de un vicio de anulabilidad en un decreto de la alcaldía de un municipio por el cual se autorizaba la domiciliación de los pagos relativos a un determinado servicio en las cuentas del ayuntamiento. El TSJ considera que la domiciliación de pagos en este supuesto es incompatible con la gestión ordenada de la disposición de los fondos públicos, vulnerando los requisitos para la ordenación del pago.

\section{Novedades doctrinales}

En relación con la actividad de la doctrina durante este 2020, debemos destacar, en primer lugar, las siguientes publicaciones sobre la aplicación del principio de estabilidad presupuestaria: M. I. AbAdÍA Jover y J. F. SÁnCHEZ GonZÁleZ, «Es tiempo de crisis: estabilidad presupuestaria y autonomía local: ¡existe alternativa?», La administración práctica, núm. 4, 2020, pp. 77-94; J. PORQUET COlOMINA, «El coronavirus, la estabilidad presupuestaria y las políticas económicas", Revista de estudios locales. CUNAL, núm. 230, 2020, pp. 62-80; G. HURTADO LÓPEZ, «Obligaciones de las entidades locales de suministro de información en el marco de la normativa de estabilidad presupuestaria y sostenibilidad financiera», El Consultor de los Ayuntamientos y de los Juzgados, núm. extra 1, 2020; R. LOSADA MUÑOZ, «Verificación del objetivo de estabilidad presupuestaria en el ámbito de las entidades locales», El Consultor de los Ayuntamientos y de los Juzgados, núm. extra 1, 2020; J. Millán SANTANA, «Los gastos con financiación afectada y la estabilidad presupuestaria», Auditoría pública, núm. extra 1, 2020, pp. 287-304; o J. M. PÉREZ ZÚNIGA, "Aspectos constitucionales de los principios de legalidad y estabilidad presupuestaria en la aprobación del gasto público», Presupuesto y gasto público, núm. 99, 2020, pp. 61-76.

Sin embargo, un aspecto integrante de la estabilidad presupuestaria, como son la regla de gasto y las reglas fiscales, ha tenido especial relevancia en los trabajos de la doctrina, destacando en esta materia los trabajos de: E. MARCO PEÑAS, «Entidades locales, disciplina presupuestaria y regla de gasto: el alcance de las restricciones de la gobernanza económica europea», en E. ARANDA ÁlLVAREZ, Las implicaciones constitucionales de la gobernanza económica europea, Tirant lo Blanch, 2020, pp. 365-417; J. J. SERRANO, «El incumplimiento de las reglas fiscales por las corporaciones locales españolas», El Con- 
sultor de los Ayuntamientos y de los Juzgados, núm. extra 1, 2020; y M. POns ReBOllo, "Aplicación de la regla del gasto en las entidades locales», El Consultor de los Ayuntamientos y de los Juzgados, núm. extra 1, 2020.

Por último, otras publicaciones relacionadas con la materia presupuestaria local y el principio de estabilidad presupuestaria destacadas en 2020 son las siguiente: G. HURTADO LÓPEZ, «La financiación de ejecuciones de sentencias judiciales firmes», El Consultor de los Ayuntamientos y de los Juzgados, núm. 8, 2020; M. C. LÓPEZ ARIAS, «Las funciones de la AIReF en materia de evaluación de la estabilidad y sostenibilidad de las entidades locales: actuaciones realizadas y perspectivas de futuro", El Consultor de los Ayuntamientos y de los Juzgados, núm. extra 1, 2020; L. TORREGROSA MirALLES, «La tutela financiera de las entidades locales. Especial referencia a la Comunidad Valenciana», El Consultor de los Ayuntamientos y de los Juzgados, núm. extra 1, 2020; E. DONOSO ATIENZA, «La deuda pública objeto de amortización con cargo al superávit presupuestario: supuestos de amortización anticipada", El Consultor de los Ayuntamientos y de los Juzgados, núm. extra 1, 2020; M. PONS REBOLLO, «Endeudamiento a largo plazo en las entidades locales», El Consultor de los Ayuntamientos y de los Juzgados, núm. extra 1, 2020; F. GARCía RUBIO, El derecho local tras la «racionalización»: entre la transparencia, la remunicipalización, y el ajuste presupuestario, Tirant lo Blanch, 2020; D. CABEZUELO VALENCIA, «Líneas fundamentales de los presupuestos para 2020 de las corporaciones locales», La administración práctica: núm. 2, 2020, pp. 209-216; E. DonOso ATIENZA, «Tres consultas relevantes formuladas al Ministerio de Hacienda por las entidades locales en materia presupuestaria», El Consultor de los Ayuntamientos y de los Juzgados, núm. 12, 2020; y R. P. RoDRÍGUEZ PÉREZ, «Los presupuestos locales desde la perspectiva de género: la elaboración del informe de impacto de género", Auditoría pública, núm. 76, 2020, pp. 77-84.

\section{EL CONTROL EXTERNO DE LA ACTIVIDAD ECONÓMICO-FINANCIERA LOCAL}

\section{La fiscalización externa de la actividad económico-administrativa de las entidades locales}

\subsection{Marco normativo en materia de fiscalización}

Respecto del marco normativo de la fiscalización de la actividad económico-financiera del sector público, debemos poner de manifiesto que no ha habido novedades normativas relevantes durante el año 2020. No obstante, debemos citar la Resolución de 15 de enero de 2020, de la Presidencia del Tribunal de Cuentas, por la que se publica el Acuerdo del Pleno de 19 de diciembre de 2019, por el que se aprueba la Instrucción sobre remisión de información relativa al ejercicio del control interno de las entidades locales.

Descendiendo al plano autonómico de la Comunidad de Madrid, debemos destacar que la normativa de la Cámara de Cuentas de la Comunidad de Madrid tampoco ha 
sufrido modificaciones relevantes a lo largo del año 2019. Debemos mencionar la Resolución de 27 de febrero de 2020, del Presidente de la Cámara de Cuentas de la Comunidad de Madrid, por la que se hace público el Acuerdo del Consejo de 27 de febrero de 2020, por el que se modifica la Instrucción que regula el formato de la Cuenta General de las Entidades Locales y el procedimiento para su rendición, aprobada por el Acuerdo de 29 de diciembre de 2015.

\subsection{Tribunal de Cuentas}

Entre la actividad fiscalizadora que el Tribunal de Cuentas ha desarrollado a lo largo del ejercicio 2020, debemos destacar algunas fiscalizaciones que se refieren específicamente a las entidades locales. En este sentido, goza de especial relevancia el Informe núm. 1.376, de 25 de junio de 2020, de fiscalización del Sector Público Local, ejercicio 2018, que recoge los resultados de los análisis realizados por el Tribunal de Cuentas sobre las cuentas generales correspondientes al ejercicio 2018 rendidas por las entidades locales. Precisamente, su objeto principal lo constituye la verificación del cumplimiento de la obligación de rendición de las cuentas por las entidades locales y el análisis de sus principales magnitudes presupuestarias, económicas y financieras.

El mencionado informe recoge los datos relativos al cumplimiento de la rendición de la cuenta general. Así, se establece que un 55 por 100 de las entidades locales rindieron su cuenta anual en el plazo legalmente establecido (pp. 26-33, vid. cuadro 4). Concretamente, un 58 por 100 de los ayuntamientos cumplieron con su obligación en ese plazo. Además, a fecha de 31 de diciembre de 2019, la rendición de cuentas de las entidades locales fue del 71 por 100, siendo del 75 por 100 en los ayuntamientos. El propio informe considera que estas cifras son inferiores a las del ejercicio 2017. Al respecto, el Tribunal de Cuentas concluye que «[e]1 $55 \%$ de las entidades locales de ámbito nacional, excluidas las del País Vasco y Navarra, rindieron la cuenta general dentro del plazo legal y, a 31 de diciembre de 2019, el nivel de rendición ascendía al 71 \% del total; porcentajes inferiores en cinco y en cuatro puntos porcentuales, respectivamente, en relación con los del ejercicio anterior y que se consideran claramente insuficientes» (p. 189).

En relación con las principales magnitudes presupuestarias, concretamente respecto del análisis del gasto presupuestario del ejercicio 2018, el mayor nivel de gasto de las entidades locales fue en bienes corrientes y prestaciones de servicios (31 por 100) y en gasto de personal (30 por 100), seguidos por el gasto en transferencias corrientes que ascendió a un 15 por 100 del gasto total (p. 54, vid. gráfico 7). Asimismo, el gasto en inversiones reales representó un 11 por 100 del gasto del ejercicio y los gastos por variación de pasivos financieros absorbieron un 7 por 100 del total. Debe subrayarse que se trata de cifras parecidas a las del ejercicio 2017.

Por áreas, destaca que el área de servicios básicos (integrada por seguridad y movilidad ciudadana, vivienda y urbanismo, bienestar comunitario y medio ambiente) es aquella que recibió un mayor nivel de recursos de las entidades locales, ascendiendo 
a un 36 por 100 del gasto total (pp. 60-62, vid. cuadro 26, gráfico 8). En segundo lugar, los programas de actividades de carácter general (incluye las políticas de órganos de gobierno, servicios de carácter general como administración general, coordinación, información básica y estadística y atención al ciudadano, entre otras) recibieron el 20 por 100 del gasto total. Asimismo, las políticas básicas de carácter preferente (contiene el gasto en sanidad, educación, cultura y deporte) se encuentran en una tercera posición con un nivel de gasto del 15 por 100 sobre conjunto, seguida en cuarto lugar por actividades de protección y promoción social (pensiones, servicios sociales de promoción social y fomento del empleo) con un 12 por 100. Curiosamente, estos porcentajes son muy similares a los del ejercicio 2017. Finalmente, debe destacarse que el área de deuda pública absorbió el 8 por 100 del gasto local en el ejercicio 2018, frente al 9 por 100 del ejercicio 2017, lo que sigue la tendencia descendiente de dicho gasto.

El informe remarca que, en 2018, el conjunto del gasto de las entidades locales aumentó un 5 por 100 respecto del ejercicio 2017 (pp. 63-65, vid. cuadro 28). En este sentido, se mantiene el cambio de tendencia iniciado en el ejercicio anterior. En concreto, hay que destacar que «[p] or tipo de entidad, los ayuntamientos de población superior a un millón de habitantes han aumentado sus gastos en un $7 \%$ en el ejercicio 2018 respecto al periodo anterior, debido fundamentalmente al aumento del gasto ejecutado en el Ayuntamiento de Madrid, que ha pasado de 4.255 millones de euros en 2017 a 4.722 millones en 2018, lo que supone un aumento interanual del $11 \%$. En los municipios del tramo de población comprendido entre 500.001 y 1.000 .000 de habitantes, el incremento interanual fue del $12 \%$ en su conjunto, destacando el Ayuntamiento de Valencia, con un incremento de sus gastos en un $36 \%$ (p. 63).

En el análisis del ingreso presupuestario se pone de manifiesto que durante el ejercicio 2018 se siguieron aprobando modificaciones de crédito financiadas con recursos imputables a los recursos de capital del presupuesto de ingresos que no se correspondían a recursos efectivamente obtenidos. Según el informe, «[1]as modificaciones presupuestarias de gastos han sido superiores en dos millones de euros a las aprobadas en el presupuesto de ingresos, debiendo estar equilibradas. En las entidades cuyo grado de ejecución en los capítulos 6 y 7 resultó inferior al $70 \%$, generalmente los derechos reconocidos en el ejercicio eran inferiores a las previsiones iniciales de dichos capítulos, por lo que las modificaciones de ingresos no daban lugar a la obtención efectiva de recursos no previstos inicialmente, incumpliendo lo dispuesto en la normativa» (p. 192).

Volviendo al análisis de los ingresos, el informe destaca la posición prevalente en media de los ingresos tributarios (55 por 100) con respecto a la financiación de las entidades locales durante el ejercicio 2018, debiéndose destacar que los impuestos directos suponen un 37 por 100 de los ingresos (pp. 70-75, vid. cuadro 34, gráfico 9). Seguidamente, las transferencias corrientes suponen el 36 por 100.

Entrando en detalle, los ingresos financieros, recurso al endeudamiento, ascendieron al 40 por 100 de los ingresos corrientes para el conjunto de las entidades locales, con un periodo mínimo de amortización igual a dos años (p. 194). En este sentido, el Tribunal 
de Cuentas concluye que "[e]l endeudamiento de las entidades locales, calculado considerando únicamente las partidas del pasivo que corresponden a obligaciones vencidas y exigibles, ha ascendido en su conjunto a un total de 17.981 millones de euros, que correspondía en un $24 \%$ del total a los ayuntamientos de más de un millón de habitantes. Dicho endeudamiento había disminuido un $10 \%$ respecto al ejercicio anterior y un $20 \%$ respecto al ejercicio precedente» (p. 194).

En cuanto a otras magnitudes económico-patrimoniales, el informe advierte un resultado económico-patrimonial positivo. Destaca un incremento de los derechos de dudoso cobro para el ejercicio 2018 situándose en un nivel del 50 por 100 sobre los derechos reconocidos pendientes de cobro a 31 de diciembre de 2018 (p. 89). Igualmente, el informe subraya una notable mejoría de la solvencia a corto plazo del conjunto de entidades locales, aunque 159 entidades locales presentan un remanente de tesorería negativo en el ejercicio (frente a las 185 del ejercicio anterior), de las cuales 124 eran ayuntamientos (pp. 89-91). No obstante, el informe incide en el hecho de que «[e]l remanente de tesorería para gastos generales total, una vez descontados los saldos de dudoso cobro y el exceso de financiación afectada, ascendió a 13.684 millones de euros, poniendo de manifiesto una situación de solvencia a corto plazo positiva. Los saldos de dudoso cobro suponían el $50 \%$ de los deudores de las entidades locales, siendo especialmente elevados en los ayuntamientos de mayor dimensión, en especial en los de población superior a 1.000 .000 de habitantes», si bien "[u]n total de 159 entidades locales presentaban remanente de tesorería para gastos generales negativo en el ejercicio, siendo las que tenían un importe más desfavorable los Ayuntamientos de Parla (Madrid), con un importe de 219 millones de euros, y los de Granada y Los Barrios (Cádiz), y el Consell Insular de Mallorca, cada uno de ellos con un importe superior a 20 millones de euros» (p. 193).

Finalmente, debemos analizar el apartado de recomendaciones (p. 199). A diferencia de informes anteriores, no se exponen unas recomendaciones de forma detallada, sino que se manifiesta que "[c]omo se ha indicado a lo largo del presente Informe y en el anterior "Informe de fiscalización del Sector Público Local, ejercicio 2017", la mayoría de las recomendaciones realizadas por el Tribunal de Cuenta en sus Informes anuales de fiscalización del sector público local, así como las correspondientes resoluciones de la Comisión Mixta para las relaciones con el Tribunal de Cuentas, se encuentran incumplidas o pendientes de su implantación definitiva, reiterándose de nuevo la necesidad de su implantación en aras de la mejora de la planificación, la gestión, la rendición de cuentas y el control sobre la actividad económico-financiera de las entidades que integran el mencionado sector público local». Esta afirmación se matiza indicando que «[s]e hace especial hincapié en la necesidad perentoria de que, por parte del Gobierno y de los Ministerios competentes, se proceda a la aplicación de la retención en los tributos del Estado que corresponda a las entidades locales que incumplan la obligación de rendir las cuentas generales, prevista en el art. 36.1 de la Ley de Economía Sostenible, así como se promueva la iniciativa legislativa oportuna para establecer como requisito, para el acceso de las entidades locales a subvenciones o ayudas públicas, estar al corriente en la rendición de cuentas al Tribunal de Cuentas y, en su caso, al respectivo órgano de Control Externo». 
Por otro lado, debemos citar diversos informes relativos a la fiscalización de las entidades locales. Concretamente, destacan el Informe núm. 1.419, de 22 de diciembre de 2020, de fiscalización de los contratos de servicios de limpieza y de vigilancia y seguridad privada celebrados por las entidades locales de las Comunidades Autónomas sin órgano de control externo propio, ejercicios 2018 y 2019; el Informe núm. 1.418, de 22 de diciembre de 2020, de fiscalización del cumplimiento de la Ley 19/2013, de 9 de diciembre, de transparencia, acceso a la información pública y buen gobierno en las entidades locales; el Informe núm. 1.417, de 22 de diciembre de 2020, de fiscalización de las tasas y precios públicos de los ayuntamientos de municipios de población superior a 500.000 habitantes, ejercicio 2017; el Informe núm. 1.416, de 22 de diciembre de 2020, de fiscalización de inmuebles en los que no se desarrolla ninguna actividad y de obras públicas paralizadas en las entidades locales de Castilla-La Mancha; el Informe núm. 1.415, de 22 de diciembre de 2020, de fiscalización de los expedientes de reconocimientos extrajudiciales de crédito aprobados por las entidades locales en el ejercicio 2018; el Informe núm. 1.406, de 26 de noviembre de 2020, de fiscalización de inmuebles en los que no se desarrolla ninguna actividad y de obras públicas paralizadas en las entidades locales de la Región de Murcia; el Informe núm. 1.405, de 26 de noviembre de 2020, de fiscalización de la promoción y gestión de la vivienda de protección pública en los Ayuntamientos de Murcia, Cartagena y Lorca, ejercicio 2018; el Informe núm. 1.403, de 26 de noviembre de 2020, anual de la Ciudad Autónoma de Ceuta, ejercicio 2018; el Informe núm. 1.399, de 29 de octubre de 2020, anual de la Ciudad Autónoma de Melilla, ejercicio 2018; el Informe núm. 1.382, de 28 de julio de 2020, de fiscalización de los gastos de personal e indemnizaciones por razón del servicio de las diputaciones provinciales y sus organismos autónomos de Comunidades Autónomas sin Organo de Control Externo propio, ejercicio 2017; y el Informe núm. 1.374, de 28 de mayo de 2020, de fiscalización de las actuaciones realizadas por las entidades locales en el marco del Plan extraordinario y urgente por el empleo de Castilla-La Mancha, ejercicios 2015 a 2017.

\subsection{Cámara de Cuentas de la Comunidad de Madrid}

La Memoria Anual de Fiscalización 2020 de la Cámara de Cuentas de la Comunidad de Madrid, aprobada por Acuerdo del Consejo de la Cámara de Cuentas de 26 de febrero de 2021, recoge que el Programa de Fiscalizaciones para el año 2020 agrupa las actuaciones fiscalizadoras en obligatorias y generales, por iniciativa de la Cámara de Cuentas, solicitadas por la Asamblea de Madrid y pendientes del programa de 2019. A lo largo del año 2020 se emitieron 9 informes, encontrándose en curso un total de 14 fiscalizaciones al término del mismo.

A diferencia de los ejercicios anteriores, durante el ejercicio 2020, no se ha aprobado el Informe de fiscalización de las Cuentas de las Corporaciones Locales, ejercicio 2018, y de las cuentas anteriores rendidas fuera de plazo. En consecuencia, a continuación se destaca una selección de aquellos informes que se encuentran directamente relacionados con la actividad económica, presupuestaria, financiera y contable de las entidades locales de la Comunidad de Madrid. 
En concreto, resulta de interés el Informe de fiscalización de los expedientes de reconocimientos extrajudiciales de créditos aprobados por las entidades locales en el ejercicio 2018 aprobado por el Acuerdo del Consejo de 20 de octubre de 2020. Como bien se recoge en su apartado de antecedentes, hay que poner de manifiesto que "[l] a figura del reconocimiento extrajudicial de créditos constituye una excepción al principio presupuestario clásico de especialidad temporal y responde a dos principios tradicionales en nuestro derecho, cuales son el de que nadie puede obtener un enriquecimiento injusto y el de que nadie puede beneficiarse de sus propios actos ilícitos», a lo que añade que "[e]l procedimiento del reconocimiento extrajudicial de crédito surge para dar respuesta a aquellas obligaciones que nacen al margen de los límites presupuestarios. Es decir, los gastos extrajudiciales se realizan al margen de la gestión del presupuesto aprobado en la entidad local ya que no respetan ni la especificidad de los créditos, ni el principio de temporalidad anual» (p. 2).

El citado informe se divide en dos partes. En la primera parte, se fiscaliza la actividad de los ayuntamientos de la Comunidad de Madrid de más de 5.000 habitantes del ejercicio 2018, esto es, 81 ayuntamientos. En la segunda parte, se lleva a cabo una muestra de las entidades estudiadas. A este respecto, como se puede leer en la delimitación del ámbito subjetivo, objetivo y temporal del informe, se solicitó información a la totalidad de los citados ayuntamientos, si bien solamente 72 de ellos respondieron al cuestionario formulado (p. 5). De los ayuntamientos que no respondieron, 8 de ellos enviaron información sobre reparos a la PRCEL, por lo que se incluyeron al análisis. El único Ayuntamiento que no proporcionó información fue el de Brunete. De los ayuntamientos analizados, 13 de ellos no rindieron su Cuenta General del ejercicio 2018 antes del 31 de diciembre de 2019, de los cuales 9 de ellos la rindieron antes del 30 de mayo de 2020 (p. 7).

Entrando a valorar los resultados de la fiscalización, debemos tener en cuenta que solamente 58 ayuntamientos han aprobado reconocimientos extrajudiciales de crédito (REC). Así, el informe recoge que «[a] lo largo del ejercicio 2018 y, sobre el ámbito de los ayuntamientos mayores de 5.000 habitantes analizados, se han imputado obligaciones al presupuesto de este ejercicio mediante la figura del REC un importe total de 73.093.628,15 euros, por parte de un total de 58 entidades. De todas ellas, el 58,50 por 100 (42.761.284,01 euros) derivan de expedientes en los que se ha omitido el trámite de fiscalización; el 30,42 por 100 (22.238.013,31 euros) son los que se han comunicado por la tercera vía comentada y en el 11,07 por 100 (8.094.330,83 euros) se producen en acuerdos adoptados contrarios a reparos formulados por los interventores respecti$\operatorname{vos}[\ldots] »($ p. 9).

Los expedientes analizados se clasifican según su origen: expedientes con omisión de fiscalización (EOF), acuerdo contrario a reparo formulado por el interventor (ACR) y comunicados por una tercera vía, estos últimos son los que se han declarado a través del cuestionario proporcionado a los ayuntamientos. Así, como se puede observar en el cuadro II. 2 y el gráfico 1 (pp. 9 y 10), los EOF constituyen el 58,50 por 100 de los REC 
analizados, mientras que el 30,42 por 100 se refieren a ACR y el resto (11,07 por 100) provienen de la tercera vía.

En cuanto a la muestra, «[s]e han seleccionado los expedientes de mayor importe de cada entidad, como norma, los superiores a 50.000 o 100.000 euros dependiendo de la entidad; además, se han incluido expedientes de menores importes de otras entidades para poder tener una mayor casuística de entidades» (p. 13). Así, prosigue exponiendo que «[d]el total de entidades y expedientes, se han seleccionado 80 expedientes de un total de 51 entidades por un importe de 36.377.666,30 euros, que representa el 49,77 por 100 del importe total. Según el origen de los expedientes, se ha revisado el 38,66 por 100 del importe de REC resultado de omisiones de fiscalización; el 11,70 por 100 del importe de los REC con acuerdos contrarios a reparos y el 49,64 por 100 comunicados por la tercera vía en respuesta a nuestro cuestionario y en los que no se ha producido ninguna de las dos situaciones anteriores». Respecto de las causas de las que derivan los REC, son la falta de consignación presupuestaria y la inexistencia de contrato por haber finalizado sin que se haya formalizado uno nuevo (pp. 18-21 y 26). En síntesis, las causas se clasifican en: facturas de los ejercicios anteriores, facturación fuera de contrato, facturación superior al precio del contrato, facturas que fraccionan el objeto del contrato pasando de menor a mayor, facturas sin consignación presupuestaria y retrasos en la tramitación.

Dada la brevedad del presente análisis, no entraremos a valorar los diferentes apartados del informe y nos centraremos en las conclusiones obtenidas (pp. 25-26). La Cámara de Cuentas de la Comunidad de Madrid considera que la normativa actual no es clara acerca de si solo pueden imputarse obligaciones de ejercicios anteriores o, por el contrario, también se admiten obligaciones del ejercicio en curso comprometidas. En este sentido, respecto de la tramitación de los REC, hay que destacar que «[e]l 87,94 por 100 de los expedientes analizados son aprobados por el Pleno de la corporación de acuerdo con el art. 60.2 del RD 500/90 y el 10,28 por 100 lo aprueba la Junta de Gobierno Local. En algunos casos han sido aprobados por el presidente de la corporación e incluso el concejal delegado». Así, el informe concluye que "[d]el total de gasto analizado en la muestra, un importe de 2.061.073,97 euros, el 5,67 por 100 ha sido tramitado correctamente pero ha sido necesaria la aprobación del REC por presentarse las facturas en el ejercicio siguiente o por retrasos en la tramitación. El 94,33 por 100 restante, un total de 34.316.592,39 euros, se han clasificado como obligaciones indebidamente comprometidas e imputadas al presupuesto de 2018», añadiendo que «[e] 56,85 por 100 del total de gasto muestreado no estaba reconocido en la cuenta 413 de Acreedores pendientes de aplicar a presupuesto, con lo que las Cuentas anuales no reflejaban información sobre estas obligaciones». Además, expone que «[e]l resultado del análisis de la cuenta de acreedores pendientes de aplicar a presupuesto pone de manifiesto que, en algunos ayuntamientos, la aplicación a presupuestos actuales de las obligaciones pendientes de ejercicios anteriores imposibilitaría la gestión anual del presupuesto», debiendo tener en cuenta que « $[1]$ a aplicación a presupuesto corriente de los gastos de ejercicios anteriores se va aplicando a distinto ritmo, llegando incluso a la no imputación de ningún importe 
y sí engrosando cada ejercicio la cifra de obligaciones pendientes». Finalmente, el informe dispone que no se ha comunicado la exigencia de ningún tipo de responsabilidad subjetiva a los órganos de gobierno y de intervención como consecuencia de la tramitación de estos expedientes.

Finalmente, la Cámara de Cuentas de la Comunidad de Madrid realiza diversas recomendaciones (p. 27), encaminadas a proponer la modificación de la regulación de los REC, así como la necesidad de dictarse instrucciones precisas. Además, considera, entre otros aspectos, que hay que reforzar los departamentos de contratación y que sería conveniente unificar los informes de los interventores.

Asimismo, debemos citar el Informe de fiscalización de determinadas áreas del Ayuntamiento de Alcobendas y sus Entidades Dependientes. Ejercicio 2016 aprobado mediante Acuerdo del Consejo de 27 de noviembre de 2020; el Informe de fiscalización del Ayuntamiento de Moraleja de Enmedio y sus Entidades dependientes. Ejercicios 2014 a 2017 aprobado mediante Acuerdo del Consejo de 10 de septiembre de 2020, el Informe de la fiscalización de la Empresa Municipal de Transportes de Madrid, S. A. U. Ejercicio 2017 aprobado mediante Acuerdo del Consejo de 27 de noviembre de 2020; y el Informe de fiscalización de determinadas áreas de la empresa municipal Madrid Destino, Cultura, Turismo y Negocio, S. A. Ejercicios 2016 a 2018 aprobado mediante Acuerdo del Consejo de 27 de febrero de 2020.

\section{Responsabilidad contable}

Junto a la labor fiscalizadora que acabamos de abordar, también es función del Tribunal de Cuentas «[e]l enjuiciamiento de la responsabilidad contable en que incurran quienes tengan a su cargo el manejo de caudales o efectos públicos» [art. 2.b) de la Ley Orgánica 2/1982, de 12 de mayo, del Tribunal de Cuentas — LOTCu—]. Así, a continuación se examinarán tanto las sentencias dictadas por la Sala de Justicia del Tribunal de Cuentas como los recursos interpuestos contra las mismas que han sido resueltos por la Sala Tercera del Tribunal Supremo.

\subsection{Tribunal Supremo}

En este ámbito material, se ha de reseñar el ATS de 13 de marzo de 2020 (ECLI:ES:TS: 2020:3267A), en el que se resolvió el recurso de queja presentado por una concejal de un grupo municipal del Ayuntamiento de Madrid (Madrid) contra el auto de la Sala de Justicia del Tribunal de Cuentas que denegó la preparación del recurso de casación.

Los antecedentes de este recurso se resumen a continuación. En primera instancia, el Tribunal de Cuentas dictó la sentencia núm. 11/2018, en procedimiento de reintegro por alcance, en relación con diversas operaciones de enajenación del patrimonio inmobiliario de la Empresa Municipal de la Vivienda y Suelo de Madrid, S. A. (EMVS) 
durante los Ejercicios 2012 y 2013. La sentencia concluyó que, como consecuencia de dichas operaciones, se había provocado un perjuicio en los fondos municipales de 25.752.103,63 euros, del cual hizo responsable a la persona que desempeñaba el cargo de consejero delegado de la EMVS y a los integrantes de la Junta de Gobierno Local del Ayuntamiento de Madrid. A continuación, los condenados interpusieron recurso de apelación, que fue resuelto por la Sala de Justicia del Tribunal de Cuentas, por sentencia núm. 13/2019 de 17 de julio (que ya comentamos en al Anuario de Derecho Municipal 2019), en la que se anuló en apelación esa primera sentencia. La Sala acogió la excepción de falta de legitimación pasiva de los miembros de la Junta de Gobierno municipal que conforman la Junta General de Accionistas de la EMVS, al no reunir aquellos la cualidad de cuentadantes y en cuanto no intervinieron directamente en las operaciones de ventas de las viviendas sujetas al régimen de protección oficial. Asimismo, la sentencia de apelación concluyó que los hechos económicos analizados no determinaban la existencia de un alcance, al no haber existido un daño económico patrimonial en los fondos públicos municipales.

Acto seguido, la ahora recurrente en queja, concejal del Ayuntamiento de Madrid, presentó escrito de preparación del recurso de casación contra dicha sentencia de apelación, invocando su condición de vecina de Madrid, y haciendo uso de la posibilidad contemplada en el art. 68.2 de la ley de Bases de Régimen Local (LBRL), tras haber requerido a la Junta de Gobierno Local del Ayuntamiento de Madrid y al consejero delegado de la EMVS a que, en cumplimiento de determinadas proposiciones aprobadas por el Pleno del ayuntamiento, preparasen el correspondiente recurso de casación.

Por su parte, la Sala de instancia denegó la preparación del recurso, al considerar que la recurrente carecía de legitimación para preparar el recurso de casación. En particular, la Sala de Justicia entiende que la legitimación por sustitución, prevista en el citado art. 68 LBRL, no resulta aplicable a la jurisdicción contable ya que la legislación reguladora del Tribunal de Cuentas contempla su propio y especial régimen jurídico para garantizar la tutela de los fondos públicos ante una eventual pasividad de la entidad pública perjudicada, lo que se articula mediante la legitimación reconocida al Ministerio Fiscal para ejercitar acciones de responsabilidad contable (art. 55.1 LFTCu) y, muy especialmente, mediante el reconocimiento de la acción pública para la exigencia de la responsabilidad contable, de acuerdo con lo previsto en los arts. 43.7 LOTCu y 56 LFTCu. Este régimen asegura que cualquier ciudadano (sea o no vecino), pueda asumir la defensa de los fondos públicos cuando considere que la entidad pública perjudicada omite la debida diligencia en dicha defensa, lo que hace innecesario que en este ámbito opere la legitimación por sustitución del art. 68.2 LBRL.

Igualmente, la Sala de Justicia razonó que, incluso prescindiendo de lo anterior, la legitimación por sustitución establecida en el art. 68.2 LBRL tiene como presupuesto inexcusable que la acción o pretensión de que se trate no haya sido ejercitada antes por la entidad municipal, sin que sea posible tal ejercicio, como se desprende de su tenor —que es reproducido literalmente por el art. 220 del reglamento de organización, fun- 
cionamiento y régimen jurídico de las entidades locales—, una vez que ya se ejercitó la acción oportuna e inicialmente.

Por su parte, el TS recuerda que en el precepto citado se establece un presupuesto de procedibilidad para comparecer en juicio en ejercicio de la acción que ahí se describe, consistente en que el vecino interesado en el ejercicio de la acción debe requerir anteriormente a la corporación municipal para que sea ella misma quien actúe, y solo ante su pasividad puede, entonces sí, promover por sí mismo, en sustitución del ayuntamiento, la acción que corresponda. A juicio del TS, este presupuesto falta en el caso que nos ocupa, pues la recurrente actúa en sede jurisdiccional en ejercicio de la acción vecinal, pero cuando se dirigió al ayuntamiento y a la empresa municipal pidiéndoles que recurrieran en casación la sentencia de apelación, no invocó el art. 68 LBRL ni advirtió en ningún momento que se amparaba en esa acción vecinal, sino que lo hizo con único apoyo en el cargo público que ostenta.

En virtud de lo anterior, se desestimó el recurso de queja, sin especial pronunciamiento sobre las costas del mismo.

\subsection{Tribunal de Cuentas}

En cuanto a la actividad de enjuiciamiento contable que desempeña el Tribunal de Cuentas, en primer lugar se ha de hacer mención de la Sentencia de la Sala de Justicia del Tribunal de Cuentas de 6 de julio de 2020, rec. 45/2019, que resolvió el recurso de apelación formulado por el jefe de negociado en los servicios municipales de intervención y tesorería del Ayuntamiento de Daimús/Daimuz (Valencia), interpuesto contra la sentencia dictada por el consejero de Cuentas en la que se estimó la responsabilidad contable por alcance del ahora recurrente.

El recurrente alega, como ya hizo en la audiencia previa, que la sentencia de instancia vulneró la excepción de litisconsorcio pasivo necesario. En particular, pone de manifiesto la existencia de otro funcionario que tenía encomendadas diferentes funciones mediante las que administraba, manejaba y utilizaba caudales o efectos públicos, por lo que debería haber sido enjuiciado como responsable contable directo en este procedimiento de reintegro por alcance.

La Sala de Justicia comienza su razonamiento recordando que en aplicación de lo dispuesto en el art. 12.2 LECiv, el litisconsorcio pasivo necesario viene impuesto por relaciones subjetivas de tal forma que si no son demandados todos aquellos que tienen un vínculo cualificado con la situación jurídica material deducida en el proceso, concurre una falta de legitimación pasiva que impide dictar una sentencia estimatoria, dado que según reiterada jurisprudencia del Tribunal Supremo y del Tribunal Constitucional, el defectuoso litisconsorcio afecta a la validez de la relación jurídico-procesal, que se entiende en estos casos mal formada. Igualmente, la Sala de Justicia del Tribunal de Cuentas ha venido sosteniendo que en el ámbito de la jurisdicción contable tiene cabida la 
excepción de litisconsorcio pasivo necesario, si bien la misma debe admitirse con criterio restrictivo y atendiendo a las circunstancias de cada caso concreto.

De los hechos probados en la instancia, la Sala concluye que la participación del recurrente en los hechos enjuiciados resulta perfectamente escindible de la que se pudiera, en su caso, atribuir al otro posible responsable. En efecto, el recurrente fue el primero que preparó fraudulentamente la documentación necesaria para hacer las transferencias ilegales y quien realizó las actuaciones precisas para que tales transferencias se realizaran, dando así lugar a un menoscabo injustificado en los fondos públicos. Asimismo, el recurrente tenía, por razón de su cargo, acceso a la documentación administrativa y presupuestaria que constituía el soporte de las transferencias antijurídicas que se realizaron y también a las cuentas bancarias del ayuntamiento de las que salieron, sin justificación, los fondos públicos con destino a patrimonios privados. Por tanto, las prácticas irregulares cometidas por el recurrente, y reconocidas por el mismo hasta el punto de haber reintegrado parte de la cantidad que se le reclama, deben considerarse suficientes por sí solas para producir los hechos enjuiciados, sin que pueda estimarse que para la producción de los mismos hubiera resultado imprescindible la actuación del pretendido litisconsorte, cuya eventual intervención en estas irregularidades no resulta inescindible de la del recurrente.

En virtud de lo anterior, se desestimó el recurso de apelación interpuesto, con imposición de las costas al recurrente.

Igualmente, se ha de dar noticia de la Sentencia de la Sala de Justicia del Tribunal de Cuentas de 6 de julio de 2020, rec. 2/2020, que resolvió el recurso de apelación formulado por el Ministerio Fiscal, interpuesto contra la sentencia dictada por el consejero de Cuentas en la que se desestimó la demanda presentada por la empresa pública INARSA, dependiente del Ayuntamiento de Arnedo (La Rioja), que pretendía la responsabilidad contable por alcance de varios miembros de la corporación y del gerente de la empresa.

El recurso de apelación se fundamenta exclusivamente en la discrepancia del Ministerio Fiscal con la apreciación de la prescripción de la responsabilidad contable en que se fundamenta el pronunciamiento desestimatorio de la demanda de la sentencia impugnada. En particular, el Ministerio Público entiende que debe ser desestimada la alegación de prescripción de la responsabilidad contable sostenida por los demandados en la primera instancia, ya que en el supuesto de autos sí concurren una serie de hechos determinantes de la interrupción del plazo de prescripción, conforme a la regulación contenida en la Disposición adicional tercera, apartado tercero, de la LFTCu. Concretamente, el apelante se refiere a que, con fecha de 11 de enero de 2016, se constituyó formalmente por el Ayuntamiento de Arnedo la denominada «Comisión Informativa Especial para analizar el estado de INARSA»; que con independencia de su denominación, el objeto de esta Comisión era realizar un examen completo de las cuentas y de la gestión de la sociedad INARSA, y, sin duda, se trató de realizar una actuación fiscalizadora; que todos los demandados fueron citados para comparecer en dicha Comisión y, además, uno de ellos llegó a comparecer formalmente; por lo demás, el Ministerio Fiscal 
también alega que tanto el informe de la Alcaldía de fecha 12 de septiembre de 2016, en el que se denuncian los hechos enjuiciados en el procedimiento de reintegro por alcance, como la denuncia formulada ante el Juzgado de Primera Instancia e Instrucción núm. 3 de Calahorra (La Rioja), fueron consecuencia directa de las sesiones y del trabajo desarrollado en la citada Comisión.

Por su parte, la Sala entiende que, para dar respuesta al recurso, es preciso analizar si la «actuación fiscalizadora» a la que se atribuyen los efectos interruptivos del plazo de prescripción de la responsabilidad contable tuvo por objeto, específicamente, «el examen de los hechos determinantes de la responsabilidad contable» que se reclama. En este sentido, entiende que atendiendo al objeto de la Comisión cabe concluir que la actividad desplegada podría incardinarse entre los procedimientos a los que la DA 3. a de la LFTCu atribuye efectos interruptivos de la prescripción, siempre que pueda establecerse que el examen de los concretos hechos que fundamentan las pretensiones de la parte actora y del Ministerio Fiscal formaba parte del objeto para el que se constituyó el órgano. Así, la Sala recuerda que el origen del pleito está en la transmisión realizada en documento público de dos parcelas de titularidad municipal (concretamente, una dación en pago de obras de urbanización), que, según la demanda, se realizó muy por debajo del valor legal de tasación de las parcelas. Sin embargo, la Sala entiende que no se ha identificado en el recurso ningún elemento concreto obrante en las actuaciones del que pueda deducirse que la posible irregularidad de la transmisión en relación con la valoración de las parcelas haya sido conocida gracias a la actuación de la Comisión.

El recurso atribuye también efecto interruptivo de la prescripción al informe de la Alcaldía en el que se denunciaban los hechos objeto de la demanda, presentado ante el Tribunal de Cuentas, y a la denuncia ante la jurisdicción penal de estos hechos que dio lugar a unas diligencias preliminares. Este razonamiento tampoco es compartido por la Sala porque lo relevante no es el conocimiento que los demandados hubieran podido o no tener de la actividad investigadora que venía desarrollando sobre su gestión anterior en la entidad pública INARSA el Ayuntamiento de Arnedo, sino el conocimiento de que se habían presentado por el ayuntamiento denuncias ante la jurisdicción penal y ante la jurisdicción contable relativas a los hechos que son objeto del procedimiento. Y, a juicio de la Sala, no cabe considerar acreditado ese conocimiento, al no estar acreditado que, antes del vencimiento del plazo de prescripción, se hubiera realizado a los demandados ninguna notificación formal de las denuncias, ni de las actuaciones a las que estas dieron lugar, ni existir tampoco elemento alguno en las actuaciones del que quepa deducir que los demandados tuvieron un conocimiento material de las citadas denuncias y actuaciones con anterioridad a la terminación del plazo de prescripción.

Como consecuencia de lo anterior, se desestimó el recurso interpuesto, sin imposición de costas.

Asimismo, se ha de reseñar la Sentencia de la Sala de Justicia del Tribunal de Cuentas de 30 de septiembre de 2020, rec. 19/2019, que resolvió el recurso del art. 41.2 de la Ley Orgánica 2/1982, de 12 de mayo, interpuesto contra la resolución del Pleno del Ayun- 
tamiento de Calamocha, por la que se acuerda declarar la responsabilidad patrimonial contable del que fuera secretario-interventor del municipio en relación a la prescripción de contribuciones especiales por determinadas obras de urbanización.

Dejando de lado las alegaciones del recurrente que ya habían sido resueltas en procedimientos anteriores, comienza la Sala analizando la excepción de cosa juzgada esgrimida por el recurrente, por haberse dictado auto de no incoación en la primera instancia del procedimiento de reintegro por alcance seguido por estos mismos hechos. A este respecto, la Sala recuerda que en el mencionado auto se resolvió que el procedimiento de reintegro por alcance no debía incoarse porque los hechos enjuiciables en el mismo no resultaban reconducibles al concepto técnico-jurídico de alcance previsto en el art. 72 de la Ley de Funcionamiento del Tribunal de Cuentas, pero en ningún caso decidió que tales hechos no pudieran generar otro tipo de responsabilidades contables. De hecho, el presente recurso del art. 41.2 LOTCu se tramita como consecuencia de un expediente administrativo de responsabilidad contable, que es uno de los cauces formales que la normativa permite para exigir, precisamente, las responsabilidades contables que no derivan de un alcance en los fondos públicos, sino de otro tipo de infracción económicofinanciera. Por tanto, ni la resolución dictada en vía administrativa por la que se exigen responsabilidades contables no derivadas de un alcance, ni la sentencia que resuelve el recurso contra dicha resolución, infringen el efecto de cosa juzgada derivado del auto de no incoación antes citado, ya que se refieren a responsabilidades contables distintas de las tratadas en dicho auto, aunque los hechos enjuiciados coincidan.

Igualmente, el recurrente adujo la caducidad del expediente de responsabilidad contable en el que se dictó la resolución que recurre. Para resolver esta cuestión, la Sala recuerda que el Tribunal Supremo, en su STS de 12 de marzo de 2019 (ECLI:ES:TS:2019:832, comentada en el Anuario de Derecho Municipal 2019), ha establecido el criterio de que el plazo de caducidad aplicable supletoriamente a los expedientes administrativos de responsabilidad contable no es el de seis meses que se establece para los procedimientos de responsabilidad patrimonial, sino el de tres meses que se recogía en el art. 44.3 de la Ley 30/1992 y se mantiene hoy en el art. 21.3 LPACAP. En aplicación de ese nuevo plazo, el procedimiento administrativo de responsabilidad contable iniciado por acuerdo del Pleno debe considerarse caducado.

La caducidad del procedimiento es decisiva para abordar la posible prescripción de la responsabilidad contable que adujo el recurrente. En efecto, teniendo en cuenta que de acuerdo con lo dispuesto en el art. 92.3 de la Ley 30/1992, aplicable al periodo en que se produjeron los hechos (en la actualidad art. 95.3 LPACAP), la caducidad no producirá por sí sola la prescripción de las acciones del particular o de la Administración, pero los procedimientos caducados no interrumpirán el plazo de prescripción. En consecuencia, debe considerarse prescrita la responsabilidad contable reclamada al recurrente, por lo que no resultó procedente entrar a conocer el resto de alegaciones.

En virtud de lo anterior, se estimó el recurso interpuesto, sin imposición de costas, anulándose la resolución del Pleno y declarándose además caducado el procedimiento 
de responsabilidad contable en el que se dictó dicha resolución y prescritas las responsabilidades contables decididas en la misma.

Igualmente, merece también ser comentada la Sentencia de la Sala de Justicia del Tribunal de Cuentas de 30 de septiembre de 2020, rec. 23/2019, que resolvió el recurso de apelación formulado por tres personas condenadas en primera instancia, interpuesto contra la sentencia dictada por la consejero de Cuentas en la que se declaró la responsabilidad contable directa en relación con distintas entidades públicas dedicadas al tratamiento de aguas residuales, por incremento injustificado de precios en las prestaciones de servicios o abono de servicios o suministros no realizados.

$\mathrm{Al}$ existir varios recurrentes, la Sala decide responder a sus recursos agrupando los argumentos esgrimidos. En primer lugar, se refiere a la posible prejudicialidad penal. Comienza recordando la Sala que ninguna de las partes ha cuestionado que los hechos enjuiciados en la causa criminal seguida en la Audiencia Provincial de Valencia sean los mismos que los que fundamentan las pretensiones de responsabilidad contable, pero esta circunstancia no es causa suficiente para acordar la suspensión alegada porque el art. 18 LOTCu establece la compatibilidad entre las jurisdicciones penal y contable por razón de la distinta naturaleza de las responsabilidades que en ellas se enjuician. Así, la caracterización legal de la responsabilidad contable como un tipo de responsabilidad jurídica de carácter reparatorio y no sancionatorio determina que el enjuiciamiento de un mismo hecho por dos jurisdicciones (penal y contable) no suponga vulneración del principio non bis in idem. Ahora bien, al poderse dictar dos resoluciones sobre los mismos hechos - una en el orden penal y otra en el contable - lo que se precisa es que ambos órdenes se pongan de acuerdo a la hora de ejecutar aquellas, en aras de evitar una duplicidad de indemnizaciones en favor de las entidades públicas perjudicadas (EMSHI, por disolución de EMARSA, y EPSAR) y, por ende, su enriquecimiento injusto.

Igualmente, la Sala rechaza la ausencia de legitimación pasiva del que fuera gerente de una de las empresas públicas, al igual que desestimó la pretensión de que la solicitud del litisconsorcio pasivo necesario, reconvertida por la consejera de instancia en petición de ampliación de la demanda, constituya una infracción de los arts. 401, 412, 420 y 426 LECiv. De hecho, a juicio de la Sala, con independencia de la forma que utilizó la consejera de instancia que, en el acto de la audiencia previa consideró, tras oír a las partes, que la petición de litisconsorcio planteada por los actores públicos debía ser considerada como una ampliación de la demanda, es de significar que las consecuencias jurídicas hubieran sido las mismas, al haber podido apreciar de oficio el litisconsorcio pasivo necesario con la consiguiente consecuencia de ordenar el emplazamiento de los nuevos demandados para que contestaran la demanda con suspensión de la audiencia.

En cuanto a la incongruencia, alegada por uno de los recurrentes, de la sentencia con otros pronunciamientos anteriores de la consejera de instancia por negar la existencia de prejudicialidad penal y, en cambio, emplear las declaraciones efectuadas en vía penal para la declaración de las responsabilidades contables y para establecer el reparto de la reparación del daño entre EPSAR y EMARSA, la Sala rechaza que haya existido, puesto 
que la valoración de la prueba con arreglo a la sana crítica es competencia exclusiva del órgano de instancia y en aquella se puede tener en cuenta todo aquello que se estime aplicable dentro de una lógica racional.

En cuanto a la alegada errónea valoración de la prueba practicada por la consejera de Cuentas, la Sala entiende que se da la correspondiente relación de causalidad entre la actuación de los condenados y el daño producido a los fondos públicos, recordando que el núcleo de actividad que corresponda a un determinado puesto puede tener suficiente relevancia objetiva como para entender que su irregular desenvolvimiento pudiera ser causa directa de los daños y perjuicios provocados, y no solo se puede incurrir en responsabilidad directa por acción, sino también por omisión, es decir, por no desarrollar la actividad que, estando incluida dentro de las funciones de la gestión encomendada, hubiera evitado los daños y perjuicios sufridos por los caudales o efectos públicos, sin que esta responsabilidad quede enervada, en modo alguno, por el hecho de que ejercitara posteriormente las acciones para el resarcimiento de los perjuicios causados.

Igualmente, ante la alegación de uno de los recurrentes consistente en que no se había acreditado que hubiera experimentado ninguna ganancia patrimonial, la Sala precisó que el alcance está definido en el art. 72 de la LFTCu como el saldo deudor injustificado en una cuenta o, en términos generales, la ausencia de numerario o de justificación en las cuentas que deban rendir las personas que tengan a su cargo el manejo de caudales o efectos públicos, ostenten o no la condición de cuentadantes ante el Tribunal de Cuentas. Por tanto, es el saldo deudor injustificado lo que origina el alcance, con independencia de que se haya producido o no una apropiación de los fondos y, en su caso, un incremento patrimonial.

En consecuencia, se desestimaron los recursos de apelación interpuestos, con imposición de costas a los recurrentes.

Por último, hemos de fijar nuestra atención en la Sentencia de la Sala de Justicia del Tribunal de Cuentas de 17 de diciembre de 2020, rec. 16/2020, que resolvió el recurso de apelación formulado por un trabajador del Patronato Municipal de Deportes del Ayuntamiento de Tomelloso (Ciudad Real), interpuesto contra la sentencia dictada por la consejera de Cuentas en la que se estimó parcialmente la responsabilidad contable del ahora recurrente, por el alcance sufrido en los fondos del mencionado organismo público.

La Sala comienza examinando la excepción de prejudicialidad penal, planteada en el recurso, por estarse tramitando a la vez que el procedimiento de reintegro por alcance, y por los mismos hechos enjuiciados en el mismo, unas diligencias previas en el juzgado de instrucción. Al respecto, la Sala recuerda que debe verificarse si concurre o no, en este caso, el requisito esencial exigido en el art. 17.2 de la LOTCu para que entren en juego las previsiones del mismo, es decir, que la cuestión prejudicial penal constituya un elemento previo necesario o decisivo para la declaración de responsabilidad contable. Así, desestima el argumento al entender que el recurrente no identifica qué decisión o decisiones de la jurisdicción penal, sobre los hechos enjuiciados en el presente procedi- 
miento de reintegro por alcance, podrían tener una influencia decisiva en la resolución que corresponde adoptar a la jurisdicción del Tribunal de Cuentas sobre las pretensiones procesales formuladas ante la misma.

Acto seguido, la Sala descarta la falta de legitimación pasiva invocada por el recurrente, ya que el propio impugnante reconoce en el recurso que estaba encargado de llevar al banco el dinero entregado, de devolver los resguardos de dicho ingreso y de entregar las liquidaciones parciales — que eran firmadas por él— al departamento de tesorería con cuanta documentación fuera necesaria para su cotejo. Ha quedado acreditado, además, que firmaba las correspondientes liquidaciones. Por tanto, tales actuaciones y cometidos convierten al recurrente en gestor de fondos públicos y en cuentadante respecto a los mismos, lo que en consecuencia le atribuye la condición jurídica de legitimado pasivo en el proceso.

En cuanto al fondo del asunto, la Sala recuerda que la responsabilidad contable del recurrente se funda en que el alcance ocasionado a los fondos públicos del patronato se produjo como consecuencia de no haberse ingresado en la cuenta bancaria municipal la totalidad del dinero cobrado en efectivo en las oficinas centrales de dicho ente público. Igualmente, quedó acreditado que el recurrente no exigió, como hubiera sido su deber, que quedara constancia de la cantidad que se le entregaba, para que pudiera comprobarse a posteriori que ingresó en el banco todo lo que se le dio. Asimismo, el recurrente era la persona que se hacía responsable, ante la tesorería municipal, de que las liquidaciones que presentaba con su firma eran fiel reflejo de los ingresos efectivamente producidos en el patronato en el correspondiente periodo. Las citadas liquidaciones no incluían la totalidad de las cantidades percibidas en efectivo en la sede central, sino únicamente las que el recurrente había ingresado en la cuenta bancaria. Finalmente, la responsabilidad del recurrente se basó en que tenía a su disposición la documentación precisa para poder comprobar que las cantidades que reflejaba el programa informático como ingresadas coincidían con las de los justificantes de TPV, resguardos de ingresos bancarios y existencias en metálico y, sin embargo, no realizó dicha comprobación.

Frente a estas constataciones que se realizaron en la instancia, el recurrente alega que el informe pericial, realizado por dos técnicos municipales, carece de la metodología adecuada y contiene errores. No es esa la conclusión de la Sala, que considera que la documentación examinada por el informe y la metodología utilizada para elaborarlo garantizan de forma suficiente y adecuada la fiabilidad de los resultados plasmados en el mismo. También adujo el recurrente que carecía de funciones de control o supervisión sobre la gestión de los fondos públicos del patronato. Este argumento tampoco convenció a la Sala, que afirmó que la responsabilidad contable del apelante no deriva de haber desarrollado incorrectamente actuaciones incluidas dentro del ámbito de las competencias atribuidas a los restantes demandados, a la tesorería o a la intervención municipales, sino de haber ejecutado de manera ilegal y, al menos, gravemente negligente las tareas propias de su cargo, que consistían en la recepción de cantidades en metálico, el ingreso de las mismas en el banco y la liquidación de las operaciones en la tesorería. Adicional- 
mente, el recurrente alegó en su defensa que había otras personas que manejaban el dinero del patronato además de él mismo. Sobre este particular, la Sala de Justicia se remite a lo argumentado en la sentencia apelada, en el que se expone con claridad por qué de la prueba practicada se desprende que el descuadre generador del alcance se produjo en el eslabón de la cadena de gestión en el que solo tenía participación el recurrente.

En definitiva, no se acogió ninguno de los argumentos del recurrente, por lo que se procedió a la desestimación del recurso, con imposición de costas.

\section{Novedades doctrinales}

En cuanto a cuestiones generales referidas al control externo, se pueden reseñar los siguientes trabajos: M. A. ABELLÁN LÓPEZ e I. BELMONTE MARTín, «Sistema político y rendición de cuentas: el caso de un órgano de control externo autonómico», en I. BELMONTE MARTín (dir.) y M. A. ABELLÁN LÓPEZ (coord.), El sistema político español: entre la memoria y el devenir, Tirant lo Blanch, Valencia, 2020, pp. 256-276; J. A. ÁlvareZ MARTín, "Control externo: de la simulación a la excelencia, propuestas", Auditoría pública, núm. extra 1, 2020, pp. 271-286; E. BENíTEZ PALMA, «La transformación digital del control externo del gasto público", Auditoría pública, núm. 76, 2020, pp. 19-30; R. FERNÁNDEZ LlerA, "Control externo y estabilidad presupuestaria: buscando el valor añadido", El Consultor de los Ayuntamientos y de los Juzgados, núm. extra 1, 2020; R. FERNÁNDEZ LLERA, «Buen gobierno local y rendición de cuentas en España», Revista de Ciencias de la Administración y Economía, vol. 10, núm. 19 (abril-septiembre), 2020, pp. 29-44; A. Figueroa LARAUDOGOITIA, «Informe jurídico sobre el control externo del presupuesto parlamentario (Parlamento Vasco. 12 de febrero de 1996)", Legebiltzarreko Aldizkaria - Revista del Parlamento Vasco: LEGAL, núm. 1, 2020, pp. 176-189; M. GARCíA ROSA, «Elaboración de recomendaciones para una contratación pública favorecedora del principio de competencia», Auditoría pública, núm. 75, 2020, pp. 117-124; M. D. Genaro MoyA, «La transformación digital en el Tribunal de Cuentas: Aprovechando las nuevas tecnologías para contribuir a la mejora en la gobernanza pública», Revista española de control externo, vol. 22, núm. extra 64, 2020, pp. 48-65; G. MARTÍNEZ MARTí y A. LLÁCER GARCÍA, "Gestión y control de los fondos públicos y publicación de las cuentas anuales de las asambleas legislativas: Caso específico de las Corts Valencianes. Una crítica constructiva", Corts: Anuario de derecho parlamentario, núm. 33, 2020, pp. 347376; L. PÉREZ SARRIÓN, «Estrategia de implantación de la administración electrónica en un órgano de control externo (OCEX): no hablamos solo de tecnología», Auditoría pública, núm. extra 1, 2020, pp. 399-422; M. Riera LÓPEZ y A. ARIAS RODRíGUEZ, «El inventario de las administraciones públicas. Reto de gestión y salvedad de auditoría», Presupuesto y gasto público, núm. 100, 2020, pp. 159-166, y L. A. SÁNCHEZ AZnAR, M. D. Guillamón López y B. Benito López, «Análisis de los informes elaborados por los OCEX: el ejemplo de la Cámara de Comptos de Navarra», Auditoría pública, núm. 75, 2020, pp. 59-72. 
En lo que se refiere a la específica función de fiscalización, se ha de dar cuenta de las siguientes publicaciones: I. CABEZA DEL SALVADOR, «El modelo de informe de auditoría de cuentas en las NIA-ES-SP», Auditoría pública, núm. 75, 2020, pp. 45-58; M. GARCÍA Rosa y S. PÉrez MENÉNDEZ, "Claves para la fiscalización del restablecimiento del equilibrio económico en los contratos de concesión afectados por la crisis sanitaria», Auditoría pública, núm. 76, 2020, pp. 85-94; M. MÉNDEZ MARTíneZ y V. ÁlVAREZ ÁLVAREZ, "Las subvenciones nominativas en los presupuestos prorrogados: problemática y fiscalización", Auditoría pública, núm. 75, 2020, pp. 161-168; A. Minguillón RoY, «La fiscalización en entornos informatizados», Auditoría pública, núm. extra 1, 2020, pp. 171-186; A. Minguillón Roy, C. GarCía y J. Soler Iranzo, «Auditoría de la ciberseguridad de los principales Ayuntamientos de la Comunidad Valenciana», Revista española de control externo, vol. 22, núm. extra 64, 2020, pp. 172-189; V. MONTESINOS JULVE, «Nuevos retos para la fiscalización de las entidades públicas», Auditoría pública, núm. extra 1, 2020, pp. 45-58; J. MurUZABAL LERGA, «La pretendida fiscalización externa del sector local», Auditoría pública, núm. 75, 2020, pp. 73-88; G. A. SÁNCHEZ LERMA, "Aspectos de legalidad en las fiscalizaciones de internalizaciones o remunicipalizaciones», Auditoría pública, núm. extra 1, 2020, pp. 381-398, y A. Teré Pérez, "La fiscalización externa de los aprovechamientos urbanísticos municipales», Auditoría pública, núm. extra 1, 2020, pp. 79-90.

En el ámbito particular de la responsabilidad contable, se ha de dar noticia de la publicación de los siguientes trabajos: E. MARCO PEÑAS, «Análisis del enjuiciamiento contable ante el Tribunal de Cuentas y el Tribunal Supremo", en S. Díez SASTRE (dir.) y C. MARTÍNEZ SÁNCHEZ (coord.), Informe sobre la Justicia Administrativa 2019: tributos, contratos públicos, responsabilidad patrimonial, derechos fundamentales, personal de la administración, protección de datos, transparencia y responsabilidad contable, CIJA-UAM, Madrid, 2020, pp. 349-421; R. RIVERO ORTEGA, Responsabilidad personal de autoridades y empleados públicos: el antídoto de la arbitrariedad, Iustel, Madrid, 2020, y T. VÁZQUEZ LÉPINETTE, "Apuntes sobre la responsabilidad de los administradores de sociedades públicas locales (Reflexiones al hilo del caso "Empresa Municipal de Transportes de Valencia, S. A. U.”)», Revista de derecho mercantil, núm. 317, 2020. 